LEARNING FROM THE PAST, BUILDING A BETTER FUTURE: EMPLOYEE MOTIVATION AND PATRON SATISFACTION
Kristina Clement \& Brianne Dosch School of Information Sciences University of Tennessee Knoxville kcleme10@vols.utk.edu bdosch@vols.utk.edu

\section{LITERATURE AND MOTIVATION}

- Historically, academic libraries struggle to provide consistent customer service (Chakraborty, 2016).

- There have been several research studies and methods implemented to address this problem (Oud \& Genzinger, 2016), all with varying degrees of long term and short term success.

- Very few of these studies include understanding the relationship between employee motivation and customer service.

- Building on select ideas of John R. DiJulius III's book Secret Service: Hidden Systems that Deliver Unforgettable Customer Service (2003), this proposed research project strives to find a meaningful way to understand employee motivation in academic libraries to actively improve the level of customer service found in academic libraries.

Please consider the following and how they affect your motivation to provide great customer service in your job.

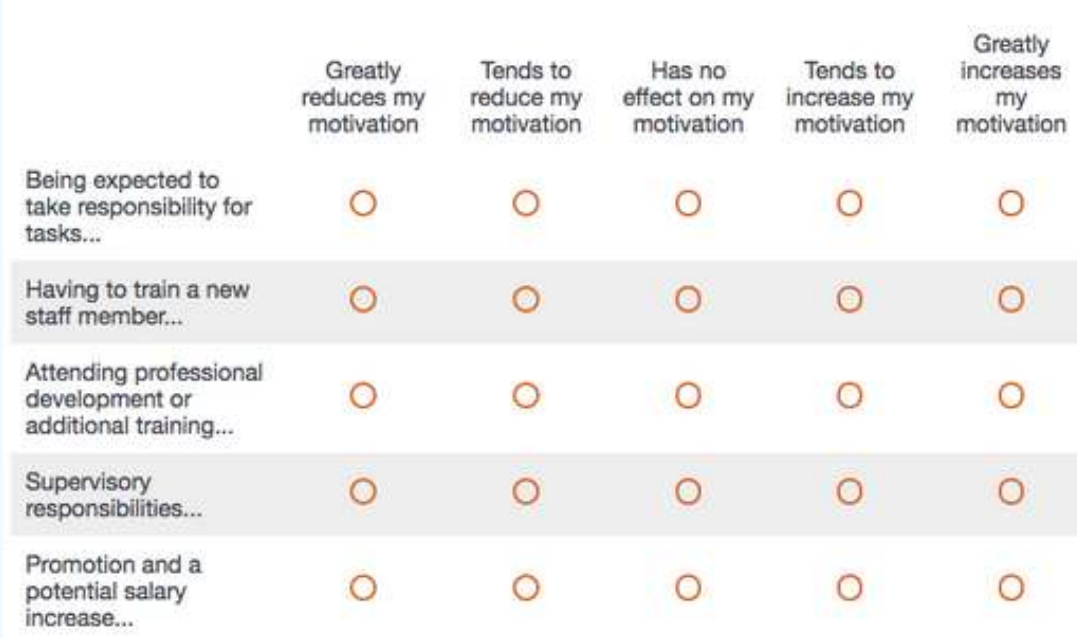

Potential Employee Survey

\section{How might understanding the underlying motivations of staff - including student \\ workers - impact the quality of customer service an academic \\ library is able to provide?}

This is a theoretical model based on current research and literature that explores whether alternative customer service models -- where more time, energy, and passion is invested in the staff who interact with the public on a daily basis -- would result in academic libraries seeing a larger return on investment in terms of student success, faculty support, brand loyalty and advocacy, and overall user satisfaction.

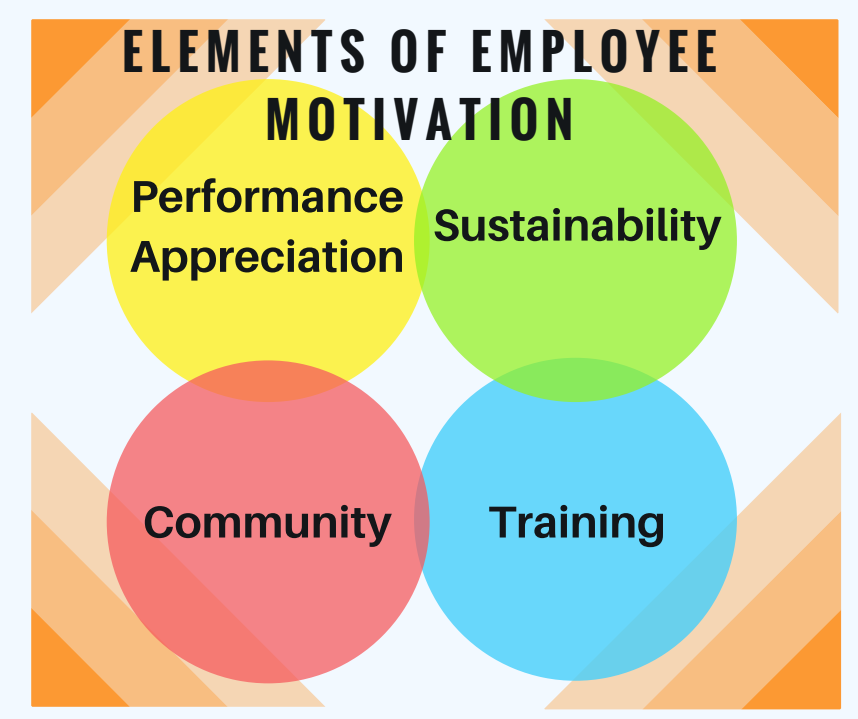

\section{PROPOSED METHODOLOGY}

- This study will consist of two phases:

- (1) Two surveys about (A) the motivation of both front-line student workers and non-faculty staff and (B) the perceptions of their supervisors regarding what they believe motivates their employees.

- (2) One-on-one interviews designed based on the results of the surveys.

- The goal is to discover the major gaps between what employees feel motivates them and what supervisors believe motivates employees and then aim to provide resources and techniques from nonacademic fields, such as business and retail to bridge the gaps.

- This research will examine working environment, professional development, and external motivators, such as personal life and flexibility.

- This project will be subject to IRB approval.

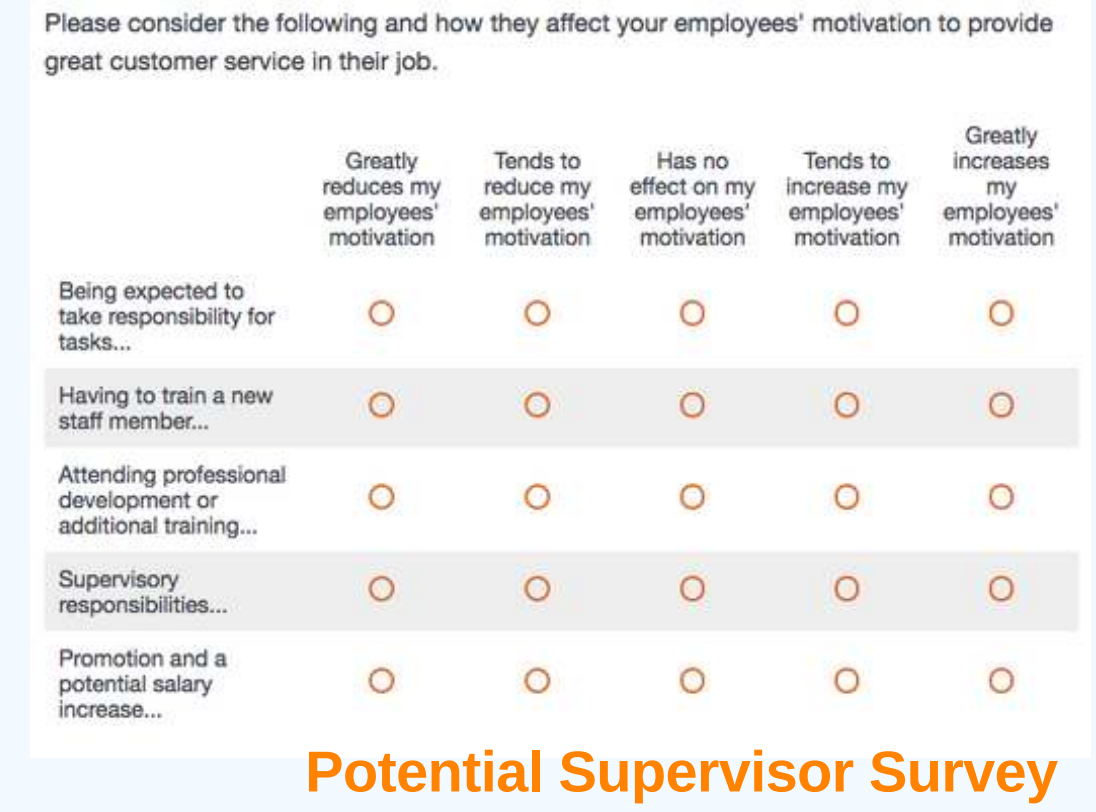

"If you treat your team members well, the majority of them will take good care of your clients." (DiJulius. 111)

"Every business begins and ends at the front desk. When people talk about terrible customer service, nine times out of ten it's based on a misstep at the front desk" (DiJulius, 53). 